\title{
THE EFFICACY OF SEXUALIZED FEMALE MODELS IN YOUNG ADULT-MALE ORIENTED CIGARETTE ADVERTISING
}

\author{
James Mark Mayer, Indiana University, USA, jammayer@iupui.edu
}

Tae Hyun Baek, Indiana University Southeast, USA, tbaek@ius.edu

\begin{abstract}
This paper explores the portrayal (efficacy) of female models in male-targeted cigarette print advertisements through a content analysis (experiment). We first describe the presence and portrayal of females through a content analysis on male-targeted cigarette advertisements in magazines; we find that, in aggregate, females are often used as sexually attractive decoration, and the overall female portrayal is fundamentally different (and unequal) to that of the male. We next investigate the efficacy of these portrayals through an experiment among young adult-aged male smokers and nonsmokers. Our experimental findings indicate that these sexually charged advertisements generate superior attitudinal results in non-smoking males than smoking males, a finding that--in conjunction with the portrayal of females in the content analysis--suggests potential societal and public policy implications.
\end{abstract}

Cigarette Advertising, Sexual Advertising, Female Portrayals, Content Analysis, Experiment

\section{INTRODUCTION}

Over the past four decades, researchers have noted that female models have become increasingly sexualized (Reichert and Carpenter 2004; Soley and Kurzbard 1986) and the cigarette industry has a decades-long history of contributing to this trend (e.g., Venkatesan and Losco 1975). Accordingly, the tobacco industry has increasingly relied on the conventional wisdom that "sex sells" to males, increasing its use of sexual themes in recent years (Sung and Hennink-Kaminski 2008).

In our first methodological section, we conduct a content analysis of young male targeted cigarette advertisements' female models (e.g., model attire) to illustrate this trend. In the second methodological section, we then explore the actual behavior of a group of individuals (young adult males) targeted by these sexualized advertisements. While adolescent smoking prevention has been the primary focus of tobacco control efforts (and academic research), this tremendous focus has resulted in a dearth of attention on young adults (18-24 years old), a group representing twice as many users, and per internal tobacco documents, a key strategic consumer for cigarette manufacturers (Ling and Glantz 2002).

We find that the addition of sexualized female models has the potential to increase male young adults' favorable attitudes towards cigarette advertising, but that it this effect is primarily isolated to male nonsmokers who don't have a smoking history (e.g., affinity and/or usage history with another cigarette brand or brands) that might dampen the female model's ability as a driver of positive attitudes. Stated simply, through both the lens of social learning theory and in the fact of government (e.g., the Master Settlement Agreement) efforts to curtail youth smoking, the two sections of the current research suggest a potentially doubly-troubling appraisal of the way females are utilized to increase young adult males' favorability towards cigarettes, and the efficacy with which this objective is accomplished.

\section{LITERATURE REVIEW}

This is the author's manuscript of the article published in final edited form as:

Mayer, J. M., \& Baek, T. H. (2016). The Efficacy of Sexualized Female Models in Young Adult-Male Oriented Cigarette Advertising. In Let's Get Engaged! Crossing the Threshold of Marketing's Engagement Era (pp. 753-766). Springer International Publishing. http://dx.doi.org/10.1007/978-3-319-11815-4_224 


\section{The Efficacy and Ethicality of Sexual Advertising}

Sexually-based appeals are more popular than ever (Gulas and Weinberger 2006), and conventional wisdom certainly suggests that "sex sells" to males but perhaps not as well to females. Some academic research seemingly confirms this assertion (LaTour and Henthorne 1993, Alexander and Judd 1986). Sengupta and Dahl (2008) further explicated these gender differences, demonstrating that while gratuitous, unnecessary use of sex in advertising is generally perceived as offensive by both women and men, fundamental gender differences (males reporting more positive attitudes towards gratuitously sexual advertisements than non-sexual ones, with the opposite true for females) do emerge in spontaneous settings.

Given that sexuality has been portrayed as the fundamental cause of gender inequality (Mackinnon 1989, Baker 2005), a higher-order consideration beyond questions of efficacy lies in the ethicality of the increased sexualization of female models in advertising. Sexual stereotyping is troubling given the media's integral role in socialization, especially into gender roles (Mackinnon 1989). Arguing for the detrimental effects of advertisements, Baker writes:

The media both reflect and reinforce traditional gender roles. Most people realize that the images in the media do not always, in fact rarely, reflect reality. However, that does not mean that these images are not influential...they help to reinforce how the ideal woman should look and behave. According to many advertisements, the ideal woman is an object that exists to satisfy men's sexual desires $(2005,13)$.

Social learning theory (e.g., Bandura 1977) provides a theoretical perspective for the importance of examining the depictions of sexual imagery in advertising. A basic tenet of social learning theory is that human behavior can be shaped and controlled by social systems. In particular, social learning theory places emphasis on the importance of observing and modeling the behaviors, attitudes, and emotional reactions of others (Bandura 1977). In other words, people can acquire knowledge, emotional reactions, and behavioral patterns by observing others' experiences or thoughts. While interpersonal learning is a primary vessel, this social learning also occurs through exposure to pervasive cultural stimuli like advertising and other media. For instance, pervasive sexual stereotyping is often thought to have farreaching effects; as Ford et al. write that "questions arise as to the impact the stereotypes may have on women, children, and society in general" $(1998,114)$. They cite studies suggesting that exposure to these stereotypes in advertising "has been found to have a causal traditionalizing effect on gender role values and detrimental effects on women's self concepts, achievement aspirations, and self images" (114).

\section{Female Sexuality in Cigarette Advertising}

Sexton and Haberman (1974) document a shift in the portrayals of women in cigarette ads from the 1950 s to the 1960 s to the 1970 s, and found that the use of women serving a purely decorative purpose in these ads jumped sharply over the studied period. This is unsurprising, as smoking has been identified as a sexually relevant product category (Reid and Soley 1983) and is intertwined with sexuality in both mainstream entertainment like films (e.g., Escamilla, Cardock, and Kawachi 2000) and in advertising (e.g., Schooler, Basil, and Altman 1996), with cigarette advertising often conveys that people who smoke have high sex appeal (NCI 2008).

When repeatedly exposed to sexual content in cigarette advertising, consumers--especially youthful ones--might view smoking behavior as desirable, rebellious, and sexy; studies suggest that youth tend to 
believe that smoking behavior conveys socially desirable attributes, such as being sexually attractive and sociable, learning not only from first-hand observation of peers, siblings, and parents who smoke, but the mass media (see Sung \& Hennink-Kaminski 2008 for a review). These components can operate directly or in tandem; for instance, Pechmann and Knight (2002) find that advertising can "persuade via a one-step process;" in other words, "cigarette ads may directly teach adolescents that smoking has symbolic and/or physiological benefits," (14) but that cigarette advertising can also increase perceptions towards smoking and thereby (even without the individual consciously realizing it) increase attitudes towards peers who smoke (an example of a two-step process). Further, the use of executional elements like sexualized female models is not simply happenstance but likely a strategic decision on the part of cigarette advertisers. As King, Reid, and Becham $(1994,74)$ write: "It is presumed that cigarette...ads, like ads for other products, are not created in a random fashion...meticulous attention is paid to every executional detail of the created ad."

Thus, consistent with social learning theory, a considerable amount of research has provided evidence that the portrayal of smoking associated with sexuality in the media and advertising can influence the smoking process in adolescents (Brown and Witherspoon 2002; Sussman 2005; Charlesworth and Glantz 2005). The 1998 Master Settlement Agreement (MSA) reached between 46 states (and five territories) and major tobacco companies did not specifically restrict magazine advertising, but did contain provisions that "no participating manufacturer may take any action, directly or indirectly, to target youths" (Krugman, Morrison, and Sung 2006, 198). While the FDA proposal for the restriction of cigarette advertising would have mandated that advertising in any publication with significant youth readership be limited to a "tombstone" text-only, black-and-white format (Krugman et al. 2006), this proposal did not ultimately pass. Rather, overall cigarette advertising spending increased post-MSA, and one particular increasing executional trend is the increased presence of sexually-themed advertising (Sung and Hennink-Kamminski 2008). In our first methodological section, we conduct a content analysis of a decade's worth of cigarette print advertising to illustrate that increased presence.

\section{METHOD ONE: CONTENT ANALYSIS}

We selected Rolling Stone (RS) and Sports Illustrated (SI) as representative male-targeted titles, since both SI and RS have primarily male readership; Mediamark Research Incorporated (MRI) estimates that as of Fall 2007, SI had an audience of 20.8 million readers (79\% male, median age of male reader $=$ 38.2) and RS's audience was 12.1 million (59\% male, median age of male reader $=30.9)$. Although both are classified as adult-oriented magazines, they each fit the FDA magazine standard of what constitutes targeting youth (Sung and Hennink-Kaminski 2008). We obtained cigarette advertisements from SI and RS by utilizing an existing database of cigarette ads prepared for the Department of Justice in tobacco industry litigation. This database contained a census of cigarette ads in these titles from 1994 to 2003.

Following a qualitative content analysis by the first author, a quantitative coding scheme was developed. We adapted variables from extant research, including articles on sex in advertising (Reichert and Carpenter 2004; Reichert and Ramirez, 20000).

Four graduate students majoring in advertising and public relations coded the cigarette advertisements after being provided a training manual featuring theoretical and practical guidance for all variables present in the study. Additionally, all coders were trained in a two-hour in-person training session where 
variables were reviewed and different examples of different levels of the variables were presented. Coders were provided with an electronic coding sheet.

We selected a sample (stratified on both brand and time) of 853 advertisements (52\% SI, 48\% RS) and $172(20 \%)$ were used in calculating inter-coder reliabilities $20 \%$ of the total set, meeting the high end of methodological recommendations (Riffe, Lacy, and Fico 1998). Reliabilities ranged from 0.85 to 0.99 , all of which were deemed acceptable as they either were equal to or greater than our minimum cutoff level of .75 (per Rust and Cooil 1994). Each of four coders coded approximately 170 advertisements.

\section{CONTENT ANALYSIS FINDINGS}

\section{Model Attire / Nudity Level}

Female models in cigarette advertisements were often dressed suggestively, exposing "skin" whereas males were very unlikely to be shown that way, especially when only one model was featured. There were repeated cases of a female whose purpose was simply to arouse the assumed male viewer and endow the cigarette advertisement with a sexual nature. Quantitative analyses confirmed gender-based differences. In the 643 advertisements featuring models, females (males) were significantly less (more) likely to be clothed demurely than males (females) $\left(\Pi^{2}(1)=48.97, p<.001\right)$ and significantly more (less) likely to be clothed in a suggestive manner $\left(\Pi^{2}(1)=128.02, p<.001\right)$ Specifically, of the 387 (512) advertisements featuring women (men), 43\% (9\%) featured at least one women (man) dressed suggestively, with 57\% (91\%)featuring at least one woman (man) dressed demurely.

Further, when only one gender was featured, females (males) in the 131 (256) female-only (male only) ads were significantly more (less) likely to be clothed in suggestive attire than were males (females) (54\% vs. 3\%), with the opposite true for demure clothing (95\% vs. $41 \%)$. This disparity also held in the subset of 252 advertisements where both males and females were present, with advertisements more likely to feature suggestively clad females than males (37\% vs. 15\%). Overall, the obvious implication is that that these cigarette advertisers are often deliberately featuring attractive, suggestively dressed females, whereas they are more likely to feature aspirationally-appropriate (whether classic such as a cowboy or more trendy such as a club-goer) demurely dressed males.

\section{Sexual Theme}

When models are present, the product meaning conveyed through cigarette advertising was generally hedonic, communicating pleasure and usage-derived sensations. However, when only females were present, advertisements were more likely to feature sexual themes (especially that of sexual attractiveness), but the presence of men made the presence of sexual themes less likely (especially in the absence of females, where this use is virtually non-existent). Overall, of the 653 advertisements featuring models, 189 (29\%) featured the theme of sexual attractiveness, 39 (6\%) featured sexual behavior, $32(5 \%)$ featured sexual voyeurism, and $30(5 \%)$ featured sexual fantasy, but these themes were virtually non-existent when female models were not present in the advertisements (all relevant chisquare tests were significant at $p<.001$ level). Just $2 \%$ of the 256 advertisements featuring only male models featured any sexually-related theme. Of the 131 (252) advertisements where only females (both males and females) were present, all of these appeals were significantly more common. Sexual attractiveness was present in 64\% (36\%) of female-only (both male and female) ads, and corresponding 
sexual behavior levels $(5 \%, 12 \%)$, sexual voyeurism $(8 \%, 8 \%)$, and sexual fantasy themes $(8 \%, 9 \%)$ were also significantly more frequent.

While our overall content analysis findings (and the post-MSA increases in sexually themed cigarette ads) may be interpreted to suggest that cigarette advertisers believe sexualized females to be an efficacious advertising strategy--after all, advertisers do not systematically employ executional variables that they believe to be inefficacious--it does not by its very nature demonstrate the efficacy of these appeals in actually selling cigarettes. In other words, while studies of advertising content "provide an empirically-based benchmark for subsequent research efforts to link the content of cigarette... ads to ad-effects" (King et al. 1994, 74), they do not themselves speak to these ad effects. We therefore supplement our content analysis with an exploratory study examining the efficacy of the sexualized female in promoting a cigarette brand to a youthful (mean age of 21.5 years old) male audience, a consumer group that is integral in tobacco industry growth efforts (Ling and Glantz 2002).

\section{THE EFFICACY OF SEXUALIZED FEMALES IN CIGARETTE ADVERTISING}

\section{Young Adult Males and Cigarettes}

Young adult males (e.g., college students) have been identified as an attractive market by cigarette industry executives (Pollay 1995). For example, Phillip Morris executives described college students as attractive since "Students are tremendously loyal. If you catch them, they'll stick with you like glue" (Pollay 1995, 3) and because "the consumer, at this age and experience level, is more susceptible to change, has far reaching influence value, and is apt to retain habits for a longer period of time than the average consumer in the general market" (Pollay 1995, 3). After reviewing over 200 relevant tobacco industry documents, Ling and Glantz (2002) suggest that tobacco marketers regard smoking initiation not as an event, but as a process, one that begins with teenagers but that must be cultivated among young adults. They write that while there has been a primary focus on youth prevention, tobacco efforts at young adults have largely been ignored:

Public health efforts dwindle at the same time that tobacco industry efforts intensify. Young adults are an important target for the tobacco industry, particularly because they face major changes in their lives. The industry studies young adult attitudes, lifestyles, values, aspirations, and social patterns with a view toward making smoking a socially acceptable part of young adults' new activities. In spite of the industry's claim that it does not market to nonsmokers, the marketing plans for young adults enable the industry to recruit new smokers between the ages of 18 and 24 years and to encourage light, occasional, or experimenting smokers to smoke more regularly. Young adults are also the youngest legal marketing target in an industry they vastly outnumber teen smokers. Furthermore, young adult who see young adults as their primary role models. $(2002,913)$

that depends on beginning smokers, and marketing promotes smoking to older teens,

Therefore, we considered college-aged males an ideal sample for a follow-up study. Our objective in this study is to compare the relative efficacy of cigarette advertisements featuring no female models with two different types of decorative female models: (1) suggestively attired, and (2) demurely attired. Additionally, we consider whether these female model manipulations would have the same influence in shaping attitudes towards cigarette advertising and the sponsoring cigarette brand among smokers and non-smokers, or if any asymmetric effects would be found.

\section{Stimulus Development}

Real-world cigarette brands have distinct brand images which we hypothesized could confound our results; therefore, we decided to use a brand that participants would have very low familiarity with. However, a benefit of utilizing a real brand would be that real-world graphics could be used in stimulus 
development, so we therefore designed advertisements for a real-life European brand of cigarettes (Rothmans), which are not easily obtained and have no market share in the United States. We designed four advertisements for use in our study. Each advertisement was constructed using Adobe Photoshop, and featured identical hedonically-themed taglines ("Rothmans. Pure Pleasure.") with a small picture of a pack of Rothmans cigarettes in the lower third of the ad, and a visual graphic in the upper section.

We designed two control ads. Both featured a scenic background, and one also had a male model smoking in the right-hand foreground of the image. We theorized that if there were no significant differences between the control ad with no male model and the second control ad featuring the male model, we could then conclude that the presence of the male model was not affecting participant attitudes (and we could then collapse these into one control condition).

Since illustrations or visuals are the most likely place for sexualized elements in advertising (Soley and Kurzbard 1986) we added appropriate images of attractive professional models to the suggestive and demure female advertisement prop portrayals (the demure model was dressed in a sweater and was from the Banana Republic clothing retailer's online catalog, and the suggestive model was dressed in a bikini and was from the Sports Illustrated Swimsuit Edition online photography archive) and inserted them on the left-hand side of the advertisement.

\section{Participants and Method}

Two hundred and six male students at a large southeastern American university participated in this study. Two-hundred three participants provided their age, and although the total range was from 19 to 39 years old, 96\% were twenty-five years old or younger. Participants were randomly assigned to a condition (one of two control ads, an ad featuring a demure female model, or an ad featuring a suggestive female model). Each participant received one advertisement as part of a booklet containing other unrelated activities. The first page of the booklet thanked them for participating, and assured them that their answers would be confidential. We asked participants to reveal their age, if they smoked cigarettes at all, and whether they considered themselves a "smoker." Finally, we asked how familiar they were with Rothmans brand cigarettes, and their attitude towards Rothmans.

The second page contained the advertisement, along with a series of questions. All questions were answered on seven-point semantic scales. We asked all participants to evaluate the ad (unfavorable / favorable) and the Rothmans brand (unfavorable / favorable).. In the conditions containing a female model as advertisement prop, an additional questions were asked: how suggestively the female model was dressed (non-suggestively / suggestively). Finally, we asked an open-ended question ("Please tell us, in your own words, why you rated this advertisement like you did in the first question."). We employed single-item (rather than multiple-item) measures since the measures related to a specific, singular object (the advertisement) and concrete attributes (e.g., attitudes). In such "doubly concrete constructs" the predictive validity of multiple-item and single-item measures is likely to be equivalent (Bergkvist and Rossiter 2007, 183). Additionally, as we were dealing with a potentially sensitive issue (smoking habits) and smokers have been found to under-report their usage (i.e. lower levels of smokers have been found when using self-reporting questionnaires versus other methods, such as nicotine levels (Gorber et al. 2009)), the use of single-item measures allowed participants to more quickly complete the study.

We randomly assigned the participants to each condition. We treated smoking status as a historical 
variable, as self-reported by participants. Of the two hundred six male participants, eighty-six participants smoked (41.7\%), but only twenty-six (12.6\%) considered themselves "smokers." Because of potential social desirability bias and historical understated self-reporting levels, we classified the eightysix participants who responded affirmatively to the question "do you ever smoke" as smokers, and the one hundred twenty who responded "no" as non-smokers.

\section{RESULTS}

\section{Familiarity with Rothmans}

Participants were overwhelmingly unfamiliar with the Rothman's brand $(M=1.07$, where $1=$ not very familiar and $7=$ very familiar). Two hundred one (97.6\%) participants rated their familiarity with the brand as a "1." We concluded that there was virtually no chance that preexisting notions about or attitudes towards the actual European-based Rothmans brand would confound the research results.

\section{Control Advertisements}

We conducted a series of one-way ANOVAs with the control conditions (without male model vs. with male model) as the independent variable, and $\mathrm{A}_{\mathrm{ad}}$ and $\mathrm{A}_{\text {Rothmans }}$ as dependent variables.. These tests revealed no significant differences between the two control advertisements (all $p \mathrm{~s}>.43$ ). In order to rule out the possibility that a specific control ad could interact with smoking status (in other words, that a control ad was preferred to the other by either smokers or non-smokers) we next conducted two ANOVAs with the same dependent variables, and both the control conditions (with vs. without male) and smoker status (smoker vs. non-smoker) as independent variables. There were no significant interaction effects present (all $p s>.28$ ). We therefore concluded that (1) the control ads could be collapsed into one level of a variable, and (2) the addition of female advertising props to the advertisement seemed appropriate methodology for testing different advertising props.

\section{Manipulation Check: Suggestive vs. Demure Female Advertisement Props}

We conducted a 2 × 2 ANOVA of female model (suggestive vs. demure) on the perceived suggestiveness of the advertisement. We tested it on all subjects in either of those two advertisement prop-variable conditions. The test revealed a main effect of female model on perceived suggestiveness $\left(M_{\text {suggestive }}=5.90\right.$ vs. $\left.M_{\text {demure }}=2.43, F(1,139)=150.91, p<.001\right)$; we concluded that the manipulation of female model (suggestive vs. demure) was successful..

\section{Findings: Main Dependent Variables}

We conducted a 3 x 2 ANOVA with female model (control vs. suggestive vs. demure) and smoker status (smoker vs. non-smoker) as independent variables, and $\mathrm{A}_{\mathrm{ad}}$ as the dependent variable. The overall model was significant $(F(5,199)=770, p<.001)$. The test revealed a main effect for advertisement prop $\left(M_{\text {control }}=2.60\right.$ vs. $M_{\text {suggestive }}=3.34$ vs. $\left.M_{\text {demure }}=2.23, F(2,199)=9.89, p<.001\right)$. Post-hoc analysis (pairwise comparisons with Bonferroni adjustment) showed that the $\mathrm{A}_{\mathrm{ad}}$ of the suggestive advertisement prop was significantly higher than that of both the control condition $(p<.02)$ and the demure ad $(p<$ $.001)$; while the control was directionally higher than the demure advertisement prop on $\mathrm{A}_{\text {ad }}$, that difference was not significant $(p>.46)$. The test also revealed a main effect for smoker status $\left(M_{\text {smoker }}=\right.$ 


$$
\left.3.06 \text { vs. } M_{\text {non-smoker }}=2.39, F(1,199)=10.08, p<.01\right) \text {. }
$$

The analysis also revealed a significant 2-way interaction of advertisement prop x smoker status $\left(M_{\text {control, }}\right.$ smoker $=3.33$ vs. $M_{\text {control, non-smoker }}=1.88$ vs. $M_{\text {suggestive, smoker }}=3.42$ vs. $M_{\text {suggestive, non-smoker }}=3.25$ vs. $M_{\text {demure, } \text { smoker }}=2.42$ vs. $\left.M_{\text {demure, non-smoker }}=2.05, F(2,199)=3.48, p<.04\right)$. Follow-up analysis confirmed mean attitudinal differences within both smoker (with suggestive and control conditions statistically equivalent, and both significantly higher than demure) and non-smoker (with control and demure conditions statistically equivalent, and suggestive significantly higher than both) conditions, at a minimum of $95 \%$ confidence level with Bonferroni adjustments. Further, these follow-up tests demonstrated that that same confidence level that the suggestive condition produced equivalent attitudes in both smokers and non-smokers.

We next conducted a similar $3 \times 2$ ANOVA with $\mathrm{A}_{\text {Rothmans }}$ as the dependent variable. Again, the overall model was significant $(F(5,199)=8.69, p<.001)$. The test revealed a main effect for advertisement prop $\left(M_{\text {control }}=2.77\right.$ vs. $M_{\text {suggestive }}=3.08$ vs. $\left.M_{\text {demure }}=2.38, F(2,199)=4.68, p<.02\right)$. Another posthoc analysis showed that $\mathrm{A}_{\text {Rothmans }}$ of the suggestive advertisement prop was significantly higher than that of the demure ad $(p<.01)$, but not the control ad $(p>.59)$, nor was the control significantly higher than the demure advertisement prop $(p>.30)$. The test again revealed a main effect for smoker status $\left(M_{\text {smoker }}=3.19\right.$ vs. $\left.M_{\text {non-smoker }}=2.29, F(1,199)=22.22, p<.001\right)$. Once again, the analysis revealed a significant 2-way interaction of model attire x smoker status on $\mathrm{A}_{\text {Rothmans }}\left(M_{\text {control, smoker }}=3.58 \mathrm{vs}\right.$. $M_{\text {control, non-smoker }}=1.95$ vs. $M_{\text {suggestive, smoker }}=3.13$ vs. $M_{\text {suggestive, non-smoker }}=3.03$ vs. $M_{\text {demure, smoker }}=2.87$ vs. $\left.M_{\text {demure, non-smoker }}=1.88, F(2,199)=5.14, p<.01\right)$.

Follow-up analysis revealed no attitudinal differences within the smoker conditions (control, demure, and suggestive conditions were statistically equivalent), but significant differences within non-smoker conditions (with suggestive significantly higher than control and demure conditions) at a minimum of 95\% confidence level with Bonferroni adjustments. Again, at that confidence level, smokers and nonsmokers were statistically equivalent in brand attitudes after viewing suggestive advertisements.

\section{Mediation Analysis}

In order to explore potential asymmetric mediation effects of suggestive advertising props on $A_{a d}$ 's influence on $A_{\text {brand }}$ for smokers and non-smokers, we created a variable called "suggestive prop presence." All participants that viewed a demure advertising prop or in the control condition were classified as " 0 " (no suggestive advertising prop present), and all participants that viewed as suggestive advertising prop were classified as "1" (suggestive advertising prop present). We then conducted mediation analyses for both participants classified as smokers and those classified as non-smokers.

The mediation analysis revealed that for non-smokers, $A_{a d}$ fully mediated the influence of suggestive advertising prop presence on $A_{\text {Rothmans. }}$. For smokers, while regressing $A_{\text {ad }}$ on $A_{\text {Rothmans }}$ revealed significant results $(p<.001)$, regressing the presence of a suggestive advertising prop on $\mathrm{A}_{\text {Rothmans }}$ showed nearly no effect $(p>.87)$. Therefore, we conclude that while for non-smokers we see full mediation, for smokers the presence of a suggestive advertising prop does have a significant effect on $A_{a d}$ but very little influence on $A_{\text {Rothmans. }}$.

\section{DISCUSSION}


As the content analysis results clearly demonstrated, cigarette manufacturers and their advertising agencies frequently employ sexual themes and sexualized models in male-targeted advertisements, suggesting that they believe these efforts to be efficacious. Our findings of this experimental study on smoking and non-smoking young adult males support that supposition.

It is not surprising that male smokers would be more receptive to control ads (with no female models) than non-smokers; they do, of course, use the product category and therefore engage in the behavior that the advertisement is featuring. These suppositions are supported by open-ended participant feedback. Non-smokers' comments made it clear in language ranging from the straightforward (e.g., "I don't smoke") to the much more colorful (including comments featuring a variety of profanity regarding smoking and those who choose to smoke) that they had no interest in either the advertisement nor the brand, whereas smokers often were either much more positive (e.g., "I like the pure pleasure line") or at least less dismissive.

It is also not surprising, given the prevalence of sex in advertising and learned gender roles, that a demurely attired female model serving a purely decorative purpose might be largely rejected by males, regardless of smoking status (feedback from two smokers was that "she's dressed like a soccer mom" and "serves no purpose", and two non-smokers responded "what the heck does that woman have to do with anything?" and "that girl looks strange there"). The obvious interpretation is that women are not effective decoration in a cigarette advertisement unless they are sexually relevant. At least in a cigarette advertisement, a demurely dressed, non-sexual (but very attractive) woman who is serving no clear purpose aside from decoration (e.g., she's not smoking) is not a positive executional element, but rather "odd and out of place.".

However, it is somewhat surprising that the addition of a suggestively attired female equalizes smokers' and non-smokers' attitudes towards the ad, raising non-smokers' (versus control) but having little effect on smokers'. Likewise, we consider it somewhat surprising that viewing a sexually themed ad featuring an attractive, suggestively dressed female had no effect on attitudes towards the Rothmans brand among smokers (versus either a control ad or even the lower-rated ad with a demure model), and perhaps even more unexpected that the impact of this sensuous model was enough to increase attitudes towards the Rothmans brand itself (and not simply the ad) in non-smokers. For the suggestive model, open-ended answers seemed to indicate that while smokers often enjoyed viewing the ad, they frequently had strong loyalty to a certain brand or wanted to know more about Rothmans (e.g., "that girl is hot but don't know about Rothman's (sic)" and "It's got a good chick but I smoke Camel Lights"). We also noticed that whereas in the control and demure conditions non-smokers would frequently say things like "I don't smoke" and "I hate smoking!" and rate attitudes toward the ad and brand very poorly, in the suggestive condition they often said the same things with less emphasis, and gave higher scores (e.g., a non-smoker who wrote "I don't smoke so this ad really isn't for me" and rated Aad 5, and another who said "she's an attractive girl but I still don't want to smoke" rated ARothmans a 5, and another who said "I'm neutral toward it. I hate cigarettes" and still assigned both Aad and ARothmans a 4). Others (both smokers and non-smokers) did consciously rate the ad higher and directly attributed that to the model (e.g., "I enjoy beautiful women and she is certainly hot" and "Quite frankly, that woman is gorgeous and I'm really just rating everything on her"). While there were also some males in both conditions that rejected the ad's blatant sexuality (e.g., "Hey, a woman in a bikini--I've never seen this before!" and "C'mon, this is so obvius (sic) with that girl"), we did not observe the same magnitude nor degree of anti-cigarette response from non-smokers as in the control and demure conditions. 
Overall, whereas smokers' brand and category familiarity seemed to allow them to look past the advertisement's blatant sexuality (even if they enjoyed it) and assign very similar scores for ARothmans regardless of the ad condition, non-smokers were much more likely to assign a positive score (even without an accompanying positive open-ended comment) when a suggestive female was present. It was as if the suggestive model flipped a switch in many non-smokers, allowing them to view something they were largely negatively aligned toward with much more tolerance and in some cases even great appreciation, a conclusion clearly supported by the mediation analysis. These non-smokers, having less expertise and no extant brand loyalties, also allow their attitudes towards advertisements inform their attitudes towards the cigarette brand.

\section{CONCLUSION}

Our findings suggest that (1) the use of sexualized females is a prevalent cigarette industry consumer communication strategy, and (2) it appears to be efficacious with a key strategic consumer. In total, if females are increasingly being stereotyped as sexual objects in male-targeted cigarette communications (and in the interest of increasing cigarette sales), this may imply two levels of societal concern: (1) as discussed previously, gender equality and socialization concerns, and (2) concern that if at-risk consumer targets (e.g., male youths and young adults) are positively influenced by these communications, they may be more likely to adopt smoking habits, counter to tobacco control efforts (e.g., the MSA). Our content analysis findings seem to support the first level of concern and our experiment supports effects that could feasibly lead to the second concern. In the final analysis, it appears that the Master Settlement Agreement left a rather effective door open to cigarette manufacturers in targeting young males (it effectively allowed a trade of stylized cartoons for stylized sexuality) and our current paper suggests that it may be a door that legislators and public policy advocates may want to undertake a more explicit attempt at closing.

\section{REFERENCES}

Alexander, Wayne and Ben B. Judd (1986), "Differences in Attitudes Toward Nudity in Advertising," Psychology, A Quarterly Journal of Human Behavior, 23: 26-9.

Baker, Christina N. (2005), "Images of Women's Sexuality in Advertisements: A Content Analysis of Black- and White-Oriented Women's and Men's Magazines," Sex Roles, 52 13-27.

Bandura, A. (1977). Social Learning Theory. General Learning Press.

Bergkvist, Lars and John R. Rossiter (2007), "The Predictive Validity of Multiple-Item Versus Single-Item Measures of the Same Constructs," Journal of Marketing Research, $44 \quad$ (May), $175-$ 84.

Escamilla, Gina, Angie L. Cradock, and Ichiro Kawachi (2000), "Women and Smoking in Hollywood Movies: A Content Analysis," American Journal of Public Health, 90 (3), 412-4.

Ford, John B., Patricia Kramer Voli, Earl D. Honeycutt, Jr. and Susan L. Casey (1998), "Gender Role Portrayals in Japanese Advertising: A Magazine Content Analysis," Journal of Advertising, 
Garber, Sarah Connor, Sean Schofield-Hurwitz, Jill Hardt, Geneviève Levasseur and Mark Tremblay (2009), "The Accuracy of Self-Reported Smoking: A Systematic Review of the Relationship Between Self-Reported and Cotinine-Assessed Smoking Status," Nicotine \& Tobacco Research, 11 (Jan), 12-24.

Gulas, Charles S. and Marc G. Weinberger (2006), Humor in Advertising: A Comprehensive Analysis, Armonk, NY: M.E. Sharpe

King, Karen Whitehill, Leonard N. Reid, Young Sook Moon, and Debra Jones Ringold (1991), "Changes in the Visual Imagery of Cigarette Ads, 1954-1986," Journal of Public Policy \& Marketing, $10(1), 63-80$.

King, Karen Whitehill, Leonard N. Reid, and Amy L. Becham (1994), "Themes and Verbal Claims in Cigarette and Alcohol Beverage Ads," Journal of Current Issues \& Research in Advertising, $16(2), 73-88$.

Krugman, Dean M., Margaret A. Morrison., and Yongjun Sung (2006), "Cigarette Advertising in Popular Youth and Adult Magazines: A Ten-Year Perspective," Journal of Public Policy \& Marketing, 25 (2), 197-211.

LaTour, Michael S., and Tony L. Henthorne (1993), "Female Nudity: Attitudes Toward the Ad and the Brand, and Implications for Advertising Strategy," Journal of Consumer Marketing, 10 (3), 25-32.

Ling, Pamela M. and Stanton A. Glantz (2002), "Why and How the Tobacco Industry Sells Cigarettes to Young Adults: Evidence From Industry Documents," American Journal of Public Health, 92 (6), 908-16.

Mackinnon, Catharine (1989), Toward a Feminist Theory of the State, Cambridge, MA: Harvard University Press.

Pechmann, Cornelia and Susan J. Knight, "An Experimental Investigation of the Joint Effects of Advertising and Peers on Adolescents' Beliefs and Intentions about Cigarette Consumption," Journal of Consumer Research, 29 (June), 5-19.

Perreault, Jr., William D., and Laurence E. Leigh (1989), "Reliability of Nominal Data Based on Qualitative Judgments," Journal of Marketing Research, 26, 135-48.

Pollay, Richard W. (1995), "Targeting Tactics in Selling Smoke: Youthful Aspects of 20th Century Cigarette Advertising," Journal of Marketing Theory \& Practice, 3 (1), 1-21.

Reichert, Tom and Courtney Carpenter (2004), "An Update on Sex in Magazine Advertising: 1983 to 2003," Journalism and Mass Communication Quarterly, 81(4), 823-37.

Reichert, Tom and Artemio Ramirez (2000), "Defining Sexually Oriented Appeals in Advertising: A Grounded Theory Investigation, " Advances in Consumer Research, 27 
267-73.

Reid, Leonard N. and Lawrence C. Soley (1983), "Decorative Models and the Readership of Magazine Ads," Journal of Advertising Research, 23 (2), 27-32.

Riffe, Daniel Lacy, Stephen and Fico, Frederick G. (1998) Analyzing Media Messages: Using Quantitative Content Analysis in Research. Mahwah, NJ: Lawrence Erlbaum Associates

Rust, Roland T. and Bruce Cooil (1994), "Reliability Measures for Qualitative Data: Theory and Implications," Journal of Marketing Research, 31, 1-14.

Schooler, Caroline., Michael D. Basil, and David G. Altman (1996), "Alcohol and Cigarette Advertising on Billboards: Targeting with Social Cues," Health Communication, 8 (2), 109-29.

Sengupta, Jaideep and Darren W. Dahl (2008), "Gender-Related Reactions to Gratuitous Sex Appeals in Advertising," Journal of Consumer Psychology, 18 (1), 62-78.

Sexton, Donald E., and Phyllis Haberman (1974), "Women in Magazine Advertisements," Journal of Advertising Research, 14 (4), 41-6.

Soley, Lawrence and Gary Kurzbard (1986), "Sex in Advertising: A Comparison of 1964 and 1984 Magazine Advertisements," Journal of Advertising, 15 (3), 46-54.

Sung, Yongjun and Heidi Hennink-Kaminski (2008), "The Master Settlement Agreement and Visual Imagery of Cigarette Advertising in Two Popular Youth Magazines," Journalism \&Mass Communication Quarterly, 85 (2), 331-52.

Venkatesan, M. and Jean Losco (1975), "Women in Magazine Ads: 1959-71," Journal of Advertising Research, 15 (5), 49-54. 